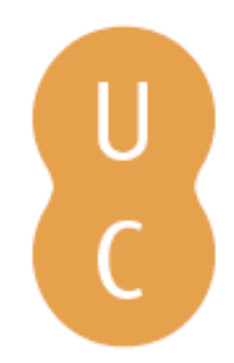

\title{
nombalina
}

\section{Platón y Lorca: filosofía en la escena (EI público)}

Autor(es): López Rodríguez, Concepción

Publicado por: Centro de Estudos Clássicos e Humanísticos da Universidade de

Coimbra; Imprensa da Universidade de Coimbra

URL

persistente: URI:http://hdl.handle.net/10316.2/30250

DOI: $\quad$ DOI:http://dx.doi.org/10.14195/978-989-721-038-9_31

Accessed : $\quad$ 26-Apr-2023 12:40:28

A navegação consulta e descarregamento dos títulos inseridos nas Bibliotecas Digitais UC Digitalis, UC Pombalina e UC Impactum, pressupõem a aceitação plena e sem reservas dos Termos e Condições de Uso destas Bibliotecas Digitais, disponíveis em https://digitalis.uc.pt/pt-pt/termos.

Conforme exposto nos referidos Termos e Condições de Uso, o descarregamento de títulos de acesso restrito requer uma licença válida de autorização devendo o utilizador aceder ao(s) documento(s) a partir de um endereço de IP da instituição detentora da supramencionada licença.

Ao utilizador é apenas permitido o descarregamento para uso pessoal, pelo que o emprego do(s) título(s) descarregado(s) para outro fim, designadamente comercial, carece de autorização do respetivo autor ou editor da obra.

Na medida em que todas as obras da UC Digitalis se encontram protegidas pelo Código do Direito de Autor e Direitos Conexos e demais legislação aplicável, toda a cópia, parcial ou total, deste documento, nos casos em que é legalmente admitida, deverá conter ou fazer-se acompanhar por este aviso.

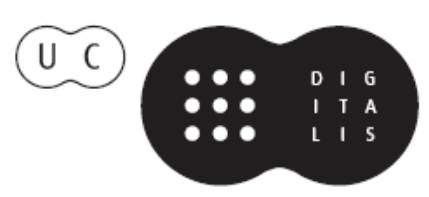




\section{De ayer a hoy}

\section{Influencias clásicas en la literatura}

\section{Aurora López, Andrés Pociña, Maria de Fátima Silva (coords.)}




\title{
Platón y Lorca: filosofía en la escena (EL PÚBLICO)
}

Concepción López Rodríguez

Universidad de Granada

\begin{abstract}
Federico García Lorca cuenta con una obra dramática titulada El público. Cuando se representó, resultó poco inteligible. Gran parte de su "extrañeza" deriva del hecho de plantear "ideas en acción”, más que contarnos una historia con personajes identificables. Un buen caudal de esas ideas halla su fuente en los diálogos de Platón, sobre todo el Banquete y el Fedro. De ellos adapta Lorca a su manera los diferentes tipos de Eros y la configuración del alma.
\end{abstract}

De todas las obras dramáticas que compuso el poeta granadino Federico García Lorca, El público ${ }^{1}$ ha sido una de las más difíciles de interpretar, tal vez por ese ropaje surrealista que la adorna pero que en definitiva no resulta tan decisivo ni tan profundo. Lo que verdaderamente caracteriza a esta obra, entre otras cosas, es la ausencia casi general de auténticos personajes con nombre propio; lo que actúa sobre el escenario son ideas y representaciones de entidades. De entre todo ese material ideológico resultan claramente perceptibles y sustanciales las aportaciones que Platón ofrece a García Lorca y que afectan tanto al contenido de la obra como a ese diseño despersonalizado de la mayor parte de sus protagonistas, al ser conceptos los que se mueven sobre el escenario, es decir "ideas" en el más puro sentido platónico.

Esta presencia del filósofo griego en la escena lorquiana no procede ex nibilo como bien ha constatado la crítica $^{2}$; una de las lecturas asiduas $\mathrm{y}$, podemos decir, preferidas de Federico son determinados Diálogos de Platón, entre los que se encuentran El Banquete y el Fedro. Sin duda, esas lecturas llevadas a cabo por el poeta granadino fecundan esta obra cuyos ejes, la verdad, el amor, la homosexualidad y la muerte se ven nutridos y definidos por la fuente inagotable de ideas del filósofo heleno que le confieren a El público la solidez de una obra de tesis. Y ¿qué tesis plantea la obra lorquina? La respuesta es múltiple pero se puede resumir de la manera siguiente: la búsqueda de la verdad.

${ }^{1}$ Las citas referentes a la obra lorquiana, El público, están tomadas de la bien realizada edición llevada a cabo por María Clementa Millán, Madrid, Cátedra, 2001.

${ }^{2}$ Por ejemplo, Rafael Martínez Nadal (El público. Amor y muerte en la obra de Federico García Lorca, Madrid, Hiperión, 1988 (3a ed. ampliada), p. 87) manifiesta: "Que en la obra de Lorca se perciban ecos de temas platónicos no debe extrañarnos; el problema del uno, de la unidad, de la reunión de mitades le preocupó siempre, sobre todo en la época en que se leía -o releía- los Diálogos Socráticos." 
En El Banquete 3 de Platón la idea de lo bello (la belleza) preside el Diálogo: a ella aspiramos en virtud del Eros (el deseo); esta idea es revelada mediante los caminos de la doxa (opinión) y el concepto de la verdad (aletheia). Tal esquema grosso modo se reproduce en El público, obra presidida por el concepto de la verdad, que, frente a las apariencias, supone la dicotomía central de la obra, cima de la pirámide por donde descienden las diversas formas de la realidad. Vinculado al concepto de verdad, supeditado a él, surge el Eros lorquiano, el auténtico, en antagonismo con el Eros de la doxa (entendida de forma negativa), aparente, esclavo de la opinión. Sin embargo, la esencia platónica, la idea, no es contemplada aquí solamente en el ámbito erótico sino que se extiende al ámbito social, expresado en el propio público, entre lo que le gusta ver y lo que debería ver, lo que quiere frente a lo que en realidad es: la verdad desnuda descarnada, desprovista de cualquier amable representación.

Si concretamos y nos acercamos a las páginas de la obra lorquiana, descubriremos, al margen del principio general expresado antes, momentos concretos, materializaciones de esa filosofía platónica dramatizada. Está claro que el tema aquí ha de supeditarse a unas breves pinceladas; espero, no obstante, que resulten claras y probatorias.

El público está estructurado en seis Cuadros. El segundo de estos Cuadros se titula "Ruina Romana", título que obedece al lugar donde se desarrolla, un espacio intermedio entre "el teatro al aire libre" y "el teatro bajo la arena"; pertenece al reino teatral subterráneo, el alejado del mundo de las apariencias, por tanto, está más cerca del teatro verdadero. En este Cuadro aparece una figura totalmente cubierta de pámpanos rojos, denominada Pámpanos, tocando una flauta sobre un capitel, y una segunda figura, Cascabeles, cubierta de cascabeles dorados, que danza en el centro de la escena. Se reconoce en la primera figura al dios del teatro, Dionisos; la significación de la segunda no ha sido aclarada del todo; existen varias propuestas: Orringer ${ }^{4}$ se inclina a pensar que se trata de una figura representativa del teatro moderno, un arlequín tal vez; en cambio, Martínez $\mathrm{Nadal}^{5}$ alude al mito de Ciso y Baco como trasfondo de estos dos personajes. Probablemente, dada la superposición de caracteres y de la acumulada simbología en casi todos los personajes y las

${ }^{3}$ Esta descripción de la filosofía del Diálogo es debida a Marcos Martínez Hernández en su Introducción a la traducción de El Banquete (Vid. Platón. Diálogos III: Fedón, Banquete, Fedro, Madrid, Gredos, 1988, p. 178).

${ }^{4}$ Dice N. R. Orringer ("Rafael Urbano`s platonic eroticism in Lorca`s theater", Ojáncano. Revista de literatura española 12, 1997, pp. 21-41): "The Figure with Red Grapevines and a flute, Martínez Nadal maintains (241-242), represents Dionysus or Bachus: the Figure wearing jinglebells, I would argue, stands for the modern clown, an ancestor of the Dionysian character".

${ }^{5}$ Rafael Martínez Nadal ha dedicado a este episodio de Pámpanos y Cascabeles una publicación específica: “Baco y Ciso”, en Cuadernos del Sur, XI, 1972, pp. 228-240. 
continuas metamorfosis, la figura de Cascabeles actúe de forma duplicada y sea a la vez uno y otro -arlequín y Ciso-, en un zeugma simbólico muy del gusto de Federico. Ambos personajes inician un diálogo, en aparente juego lingüístico sin trascendencia, de continuas propuestas de metamorfosis. " $\dot{b}$ Si yo me convirtiera en una nube?”, dice Cascabeles. Responde la figura de Pámpanos: "Yo me convertiría en ojo". Pero, más allá del simple entretenimiento, las palabras de uno y otro, en su burlesco tono, exponen las constantes alternativas del ser. En una de estas propuestas, dice Cascabeles: " ${ }_{\dot{b}} Y$ si yo me convirtiera en pez luna?" Responde Pámpanos: "Yo me convertiría en cuchillo". El pez luna y el cuchillo son símbolos recurrentes en la obra lorquiana y están cargados de erotismo.

El juego de las metamorfosis propuestas no carece de significado, a pesar de esa "aparente ingenuidad". Consideremos el "pez luna", sus vinculaciones con la "unidad del ser" y su trasfondo platónico. Para ello, previamente, hemos de exponer algún fragmento del diálogo perteneciente a este segundo Cuadro ("Ruina Romana"). Las palabras más significativas del mismo se pronuncian inmediatamente después de la entrada en escena de un Niño que cae del techo vestido con una malla roja y después de la entrada del anunciado Emperador de los romanos y de su Centurión; además, también aparecen en escena los cuatro Caballos con sus trompetas; estos Caballos son protagonistas destacados de la obra junto con los diferentes tipos de Hombres (I, II, III) y poseen una clara ascendencia platónica ${ }^{6}$. En el mencionado diálogo entre el Centurión, la figura de Pámpanos, la figura de Cascabeles y el Emperador se plantea la búsqueda del "uno":

Centurión. El Emperador busca a uno.

Figura de Pámpanos. Uno soy yo.

Centurión. ¿Cuál de los dos?

Figura de Pámpanos. Yo.

Figura de Cascabeles. Yo.

Centurión. El emperador adivinará cuál de los dos es uno. Con un cuchillo o con un salivazo. ;Malditos seáis todos los de vuestra casta!

La relación entre ese "pez luna" y el tema de la "unidad del ser" podrá entenderse mejor si acudimos a las fuentes platónicas. Cuando Aristófanes en El Banquete toma la palabra, introduce un elemento, principal motor, que se

${ }^{6} \mathrm{El}$ importante valor de los Caballos y su vinculación al mito platónico del alma concebida como "la conjunción de fuerzas que hay entre un tronco de alados corceles y un auriga" ha sido puesto de relieve por mí en otro trabajo. Vid. Concepción López Rodríguez, "Los caballos del alma: el sustrato platónico de El público de Federico García Lorca”, incluido en La tradición clásica en la obra de Federico García Lorca (ed. José María Camacho Rojo, Granada, Universidad de Granada, pp. 461-493). 
debe anexar, en el análisis de El público, a los dos anteriormente citados ("pez luna" y "la unidad"): se trata de Eros, la dynamis del ser. Dice Aristófanes, al explicar la naturaleza humana cuya raíz es precisamente ese Eros:

"En primer lugar, tres eran los sexos de las personas, no dos, como ahora, masculino y femenino, sino que habia, además, un tercero que participaba de estos dos, cuyo nombre sobrevive todavía, aunque el mismo ha desaparecido. El andrógino, en efecto, era entonces una cosa sola en cuanto a forma y nombre, que participaba de uno y otro, de lo masculino y lo femenino, pero que abora no es sino un nombre que yace en la ignominia. En segundo lugar, la forma de cada persona era redonda en su totalidad, con la espalda y los costados en forma de circulo [...] Como llegaron a ser poderosos los hombres, incluso para los dioses, tras pensarlo detenidamente, dijo, al fin, Zeus: me parece que tengo el medio de cómo podrían seguir existiendo los hombres y, a la vez, cesar de su desenfreno haciéndolos más débiles y más útiles para nosotros, por ser más numerosos [...] Dicho esto, cortaba a cada individuo en dos mitades [...]. Así, pues, una vez que fue seccionada en dos la forma original, añorando cada uno su propia mitad se juntaba con ella y rodeándose con las manos y entrelazándose unos con otros, deseosos de unirse en una sola naturaleza, morian de hambre y de absoluta inanición, por no querer hacer nada separados unos de otros. Desde hace tanto tiempo, pues, es el amor de los unos a los otros innato en los hombres y restaurador de la antigua naturaleza humana. Por tanto, cada uno de nosotros es un simbolo de hombre [...] al haber quedado seccionado en dos de uno solo"'.

Más adelante dice Platón (192d) en un texto sobre el mismo tema, muy interesante: "Amor es, en consecuencia, el nombre para el deseo y la persecución de esa integridad".

La idea de fusión entre las dos partes que conforman al ser enamorado no es una idea o expresión puntual que aparezca solo en este contexto de $\mathrm{El}$ público y que afecte solo a la figura de Pámpanos y Cascabeles, por ejemplo; también afecta a la relación de Pámpanos con el Emperador, como se deduce de las palabras que intercambian, y supone una constante en toda la obra: la ambición de la unidad primigenia caracteriza las ansias del Director con el Hombre I (Enrique-Gonzalo, los dos únicos protagonistas principales que tienen nombre propio). Según se desprende del resto de la pieza, el poeta granadino no encuentra una solución esperanzadora a esa búsqueda porque la unión total fracasa en la muerte que anula el Eros o, desde otro punto de vista, lo culmina.

El símbolo de unidad que representa el pez luna sigue persistiendo hasta el final de la obra. Veamos unas palabras del Cuadro sexto:

${ }^{7}$ Vid. Platón, El Banquete, 189 e y ss. La cita pertenece a la traducción de Marcos Martínez, Op. Cit., pp. 222 y ss. 
Señora. ¿̇Dónde está mi hijo? Los pescadores me llevaron esta mañana un enorme pez luna, pálido, descompuesto, y me gritaron: ;Aqui tienes a tu hijo!

La Señora recibe en sus brazos el cadáver de su hijo, el Hombre I, transformado en pez-luna; el hombre tal vez haya logrado satisfacer sus deseos, pero está muerto.

Si damos un paso más, encontraremos también en Platón un cercano paralelo a este lorquiano pez luna. Para ello, citaremos las ilustradoras palabras de Luis Martínez Cuitiño ${ }^{8}$ :

"La complicación simbólica del pez luna radica en que constituye una construcción bíbrida que tiene en una de sus caras a la luna-andrógino, pero Lorca innova creando un simbolo personal transformando el otro miembro del andrógino en pez. Para hallarle explicación a la presencia del pez hay que volver al discurso de Aristófanes en El Banquete de Platón. Alli Aristófanes metaforiza la condición el hombre con el lenguado: "cada uno de nosotros es una contraseña de hombre, al haber quedado seccionados, como los lenguados, en dos de uno que éramos (Platón, 1999, 84)”.

Fracasa, en un sentido, la añorada culminación del Eros, porque tras ella no existe nada, solo una verdad inmutable, universal y constante, no producto de la doxa sino de la episteme: la muerte que, como hábil Prestidigitador (es un personaje que aparece al final de la obra) ha manipulado nuestros continuos deseos.

\footnotetext{
${ }^{8}$ Vid. Luis Martínez Cuitiño, El mito del andrógino, Buenos Aires, Corregidor, 2002, p. 60.
} 